\title{
Research On Machining Non-Orthogonal Face Gears By Power Skiving With Tooth Flank Modification Based On Six-Axis Machine Tool
}

\section{Han ZHENGYANG}

Northwestern Polytechnical University

Jiang CHUANG

Henan University of Science and Technology

Deng Xiaozhong ( $\sim$ LYDXZ01@163.com)

Henan University of Science and Technology

\section{Research Article}

Keywords: Non-orthogonal face gear, Power skiving, Tooth flank modification, Gear cutting

Posted Date: November 10th, 2021

DOI: https://doi.org/10.21203/rs.3.rs-1042914/v1

License: (c) (i) This work is licensed under a Creative Commons Attribution 4.0 International License.

Read Full License 


\title{
Research on machining non-orthogonal face gears by power skiving
}

\author{
with tooth flank modification based on six-axis machine tool \\ Han ZHENGYANG ${ }^{1}$, Jiang CHUANG ${ }^{2,3}$ and Deng XIAOZHONG ${ }^{2,3}$ \\ Corresponding author: Deng XIAOZHONG \\ E-mail: dxz01@163.com \\ 1. School of Mechatronic Engineering, Northwestern Polytechnical University, \\ 127 Youyi West Rd, Xi'an 710072, China \\ 2. School of Mechatronics Engineering, Henan University of Science and Technology, \\ 48 Xiyuan Rd, Luoyang 471003, China \\ 3. Collaborative Innovation Center of Machinery Equipment Advanced Manufacturing, Henan University of Science and \\ Technology, \\ 48 Xiyuan Rd, Luoyang 471003, China
}

\begin{abstract}
To solve the manufacturing difficulties of non-orthogonal face gear, an efficient gear machining method referred to as power skiving is proposed. The machining principle of the power skiving and the relative position between the cutter tool and the workpiece are analyzed. Then, the mathematical model of machining non-orthogonal face gears by power skiving is established and the tooth flank equation is obtained. The installation and movement mode of non-orthogonal face gears on six-axis machine tool are analyzed and the machining parameters are calculated precisely. A method of tooth flank modification on the six-axis machine tool is presented by changing the machining parameters. The meshing performance of the obtained non-orthogonal face gear is analyzed by an example. Finally, the processing test and the tooth flank measurement are carried out. The experimental results show that the non-orthogonal face gear can be machined and modified by power skiving on the proposed six-axis machine tool.
\end{abstract}

Keywords Non-orthogonal face gear; Power skiving; Tooth flank modification; Gear cutting

\section{Introduction}

Face gear drives are the precision mechanical transmission matching cylindrical gears to bevel gears. When the cone angle of bevel gear is not $90^{\circ}$, which is called non-orthogonal face gear, it can be used in some non-orthogonal transmission mechanisms, such as helicopter tail transmission, ship propeller and so on. When the cone angle of the bevel gear is $90^{\circ}$, called orthogonal face gears, the teeth of it will be distributed in a plane. Due to the pinion is a cylindrical gear, face gear drives inherit some advantages of cylindrical gear drives, such as insensitive to installation error, the axial position of cylindrical gear has no influence on the contact performance and so on. Face gear drives perform excellently in power splitting, big transmission ratio, low noise and high strength, so it can be used in helicopter main reduction boxes [1].

Face gear drives were first proposed by Buckingham [2] in 1949. In the 1990s, Professor Litvin's team [3-6] carried out a series of researches and discussions on theoretical design and tooth surface modification of face gears and achieved considerable results. In addition, Wang et al. [7, 8] studied honing and griding method for face gears with tooth profile modification. Chu et al. [9] presented a novel method for grinding face gear along contact trace using disk CBN wheel. Kawasaki et al. [10] clarified the effect of the helix angle on the composition of the surface contact lines and proposed a geometric design method that recognizes meshing singularity. At present, the design and calculation 
of face gears have a plentiful theoretical foundation. The machining technology of face gears mainly relies on the basic theory of generating surface by gear shaping. Machining methods include face gear hobbing [11], CONIFACE [12], gear milling on machining centers, gear shaping, and powder metallurgy forming. However, these machining methods are mainly aimed at the orthogonal face gears. Due to the particularity of $90^{\circ}$ cone angle of orthogonal face gears, it is easier to implement manufacture of the orthogonal face gear in Cartesian coordinate system machine tools. As for nonorthogonal face gear, the machine tool needs to be more flexible due to the diversity of its cone angle. Non-orthogonal face gears are machined mainly rely on the machining center so for. The tooth groove generated by milling cutter on machining center will be limited by the size of the milling cutter. Thus, it is difficult to manufacture the tooth root surface with small transition arc.

Aiming at the difficulties of machining non-orthogonal face gears, this paper proposed machining non-orthogonal face gears by power skiving on the proposed six-axis machine tool. Power skiving, which was proposed by Pittler [13] as early as 1910, is continuous efficient processing method for cylindrical gears. Power skiving requires accurate rotating speed ratio between the cutter tool and the workpiece at high speed. However, due to lacking of proper processing equipment, this novel processing method was not applied in industrial manufacture at that time. With the development of $\mathrm{CNC}$ machine tool technology and tool materials, power skiving is gradually favored by industrial development and has been studied by scholars around the world in recent years. For example, Guo et al $[14,15]$ conducted the fundamental research on the cutting mechanism of cylindrical gear power skiving and proposed a method to design and calculate the skiving tool with the modification coefficient and the tapered teeth for machining involute gears. Chung et al. [16] proposed a simple methodology for automatically and systematically generating the $\mathrm{NC}$ code required to manufacture gears using the power-skiving method on a conventional six-axis CNC turn-mill machining center. Numerical control system and tool material technology give full play to high efficiency cutting characteristics of power skiving. However, this gear machining method is only applied to the cylindrical gears at present, especially for internal gears. As for machining face gears by power skiving, there is no relevant information about it so far.

In this paper, power skiving is used for machining non-orthogonal face gears. The processing motion conversion in the proposed six-axis machine tool is realized. An approach to realize tooth surface modification on the machine tool is also presented. An experiment is carried out finally. The results of calculation and experiment show that power skiving is an effective machining method for non-orthogonal face gears. This processing method for machining non-orthogonal face gears can be realized on the six-axis machine tool proposed in this paper.

In this paper, $S$ represents the Cartesian coordinate system. $\boldsymbol{M}_{m n}$ represents the transformation matrix (4×4) from $S_{n}$ coordinate system to $S_{m}$ coordinate system (refer to Appendix A). $\boldsymbol{T}_{m n}$ represents the transformation matrix ( $3 \times 3)$ after removing the last row and the last column of $\boldsymbol{M}_{m n}$.

\section{Machining scheme of non-orthogonal face gear}

The relative cutting speed of power skiving is generated by the rotation of the cutter and the workpiece around their own axes, which are situated in a nonzero shaft angle. Taking the internal gears for example, the shaft angle between the cutter axis and the internal gear axis is $\Sigma_{0}$ (see Fig. 1). $a_{1}$ is the axis of the internal gear and $a_{c}$ is the axis of the cutter. $\omega_{1}$ and $\omega_{c}$ are the angular speeds of the internal gear and cutter, respectively. The power skiving cutter can be regarded as a helical gear specially treated. For example, the tooth crest can be designed as a cone to provide the relief 
angle of the cutter. The pitch circle of the cutter is tangent to the pitch cylinder of the internal gear at point $O . V_{1}$ and $V_{c}$ are the linear velocities generated by the internal gear and the cutter, respectively. The relative cutting speed $V_{c 1}$ provides the cutting motion for the processing. At the same time, the translational motion of the cutter along direction of the axis of the internal gear provides feed motion. The following relation should be satisfied:

$$
z_{c} \omega_{c}=\omega_{1} z_{1}
$$

where $z_{c}$ and $z_{1}$ is the number of teeth of the cutter and the internal gear, respectively.

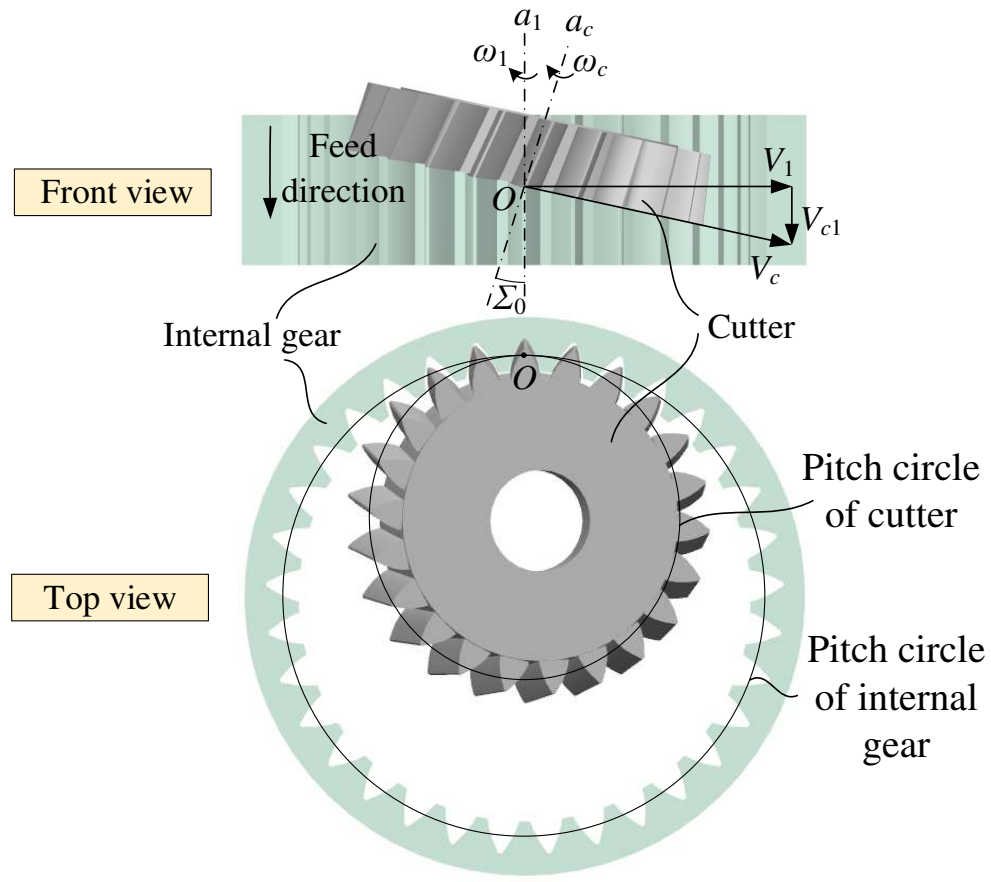

Fig. 1 Power skiving for internal gear

On the above theoretical basis, we can further extend the processing of face gear. Machining face gears by power skiving as shown in Fig. 2 can be conceived. We assume that the tooth of the internal gear corresponds to the tooth of the face gear at point $O$, the pitch cone of the face gear will be tangent to the pitch circle cylinder of the internal gear. Thus, the position of the cutter and the face gear will be visualized. In Fig. 2, $a_{f}$ is the axis of the face gear, $\omega_{f}$ is the angular speed of the face gear. At this point, the axis of the face gear will intersect the axis of the internal gear by a shaft angle $\Sigma$. The feed motion still provided by the translational motion of the cutter moving along the direction of the axis of the internal gear. The following relationships should be satisfied in the machining scheme:

$$
z_{c} \omega_{c}=\omega_{1} z_{1}=z_{f} \omega_{f}
$$

As can be seen in Eq. (2), the angular speed of cutter and face gear only needs to meet the ratio of teeth. The internal gear as a fictitious medium no longer affects the motorial relationship between the cutter and face gear. In the machining process, only three movements are needed which include the rotation of the cutter, the rotation of the workpiece, and the feed motion of the cutter along the axis of the fictitious internal gear. 


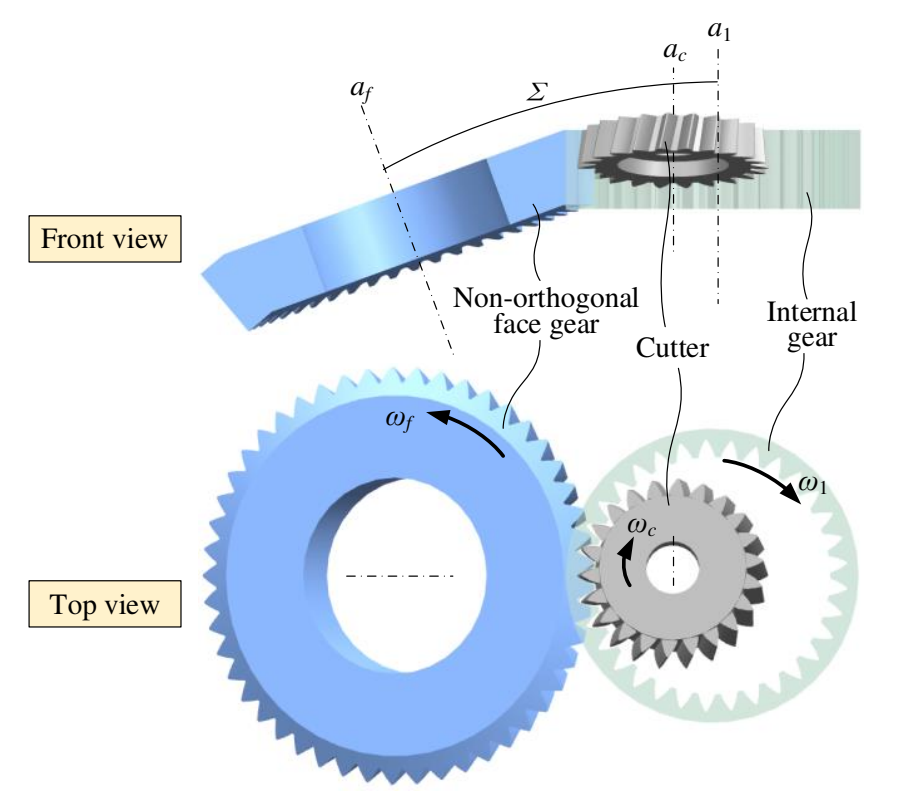

Fig. 2 Power skiving for non-orthogonal face gear

\section{Machining mathematical model}

The tooth surface of face gear is machined by the cutting edge of the power skiving cutter through the continuous cutting method. The coordinate data of the tooth surface can be obtained by mathematical model. The coordinate data of the tooth surface is a necessary condition for measuring bevel gears. In this section, the mathematical model of non-orthogonal face gear machined by power skiving is established. The tooth surface equation will support the subsequent measurement and evaluation tasks.

Figure 3 is the coordinate system of machining non-orthogonal face gear by power skiving. The coordinate system $S_{c}$ is fixedly connected fixedly with the cutter. $Z_{c}$ overlaps the axis of the cutter. Coordinate system $S_{f}$ is fixedly connected with the workpiece, $X_{c}$ overlaps the axis of the workpiece. In the machining process, $S_{1}$ is the starting position of $S_{c} . \varphi_{c}$ is the rotation angle of the cutter around its own axis. $S_{4}$ is the starting position of $S_{f} . \varphi_{f}$ is the rotation angle of the workpiece around its own axis. $S_{2}$ and $S_{3}$ are the auxiliary coordinate systems. $Z_{2}$ is parallel to the pitch cone generatrix of the workpiece. $\beta_{c}$ is the angle between the cutter axis and the pitch cone generatrix of the workpiece. When the spiral angle of the face gear is $0, \beta_{c}$ will equivalent to the helix angle of the cutter. $Z_{2}$ overlaps $Z_{1} . S_{3}$ is parallel to $S_{4}$ and $Y_{3}$ overlaps $Y_{2} . \Sigma$ is the shaft angle of non-orthogonal face gear pair. The point $O$ is the intersection of pitch circle of cutter and $X_{1}$. The point $O_{a}$ locates in the pitch cone generatrix of non-orthogonal face gear as well as in $X_{1} . d_{s}=O_{a} O_{f}$ denotes the spatial position of the cutter relative to the workpiece. The point $O_{i}$ is the projection of $O_{a}$ on $X_{4}$. The point $C$ is the projection of $O_{c}$ on $X_{4}$.

According to the theory of coordinate transformation, the equation of any point on the tooth surface of non-orthogonal face gear in $S_{f}$ can be expressed as:

$$
\boldsymbol{r}_{f}\left(\varphi, \varphi_{c}, d_{s}\right)=\boldsymbol{M}_{f c}\left(\varphi_{f}, a_{1}, a_{2}, d_{s}, \Sigma, \beta_{c}, \varphi_{c}\right) \boldsymbol{r}_{c}(\varphi)
$$

where $\varphi$ is the parameter of the cutting edge, $\boldsymbol{r}_{c}$ is the expression of the cutting edge of cutter. The cutter can be regard as a helical gear. The cutting edge can be regard as standard involute formed in the end face of the cutter. 
The transformation matrix is:

$$
\boldsymbol{M}_{f c}\left(\varphi_{f}, a_{1}, a_{2}, \Sigma, \beta_{c}, \varphi_{c}\right)=\boldsymbol{M}_{f 4}\left(\varphi_{f}\right) \boldsymbol{M}_{43}\left(a_{1}, a_{2}\right) \boldsymbol{M}_{32}(\Sigma) \boldsymbol{M}_{21}\left(\beta_{c}\right) \boldsymbol{M}_{1 c}\left(\varphi_{c}\right)
$$

where

$$
\left\{\begin{array}{l}
a_{1}=\overline{O_{c} C}=d_{s} \sin \Sigma+\left(r_{0}-\xi\right) \cos \Sigma \\
a_{2}=\overline{O_{f} C}=d_{s} \cos \Sigma-\left(r_{0}-\xi\right) \sin \Sigma \\
\varphi_{f}=\varphi_{c} z_{c} / z_{f} \pm \Delta d_{s} \sin \beta_{f} /\left(\pi m z_{f}\right)
\end{array}\right.
$$

where $\xi$ indicates the excess in-feed (which will be used in the modification part below). $\Delta d_{s}$ is the variation of $d_{s} . r_{0}$ is the pitch radius of the cutter. The sign " \pm " indicates the hands of non-orthogonal face gear.

The unit normal vector of the tooth surface is:

$$
\boldsymbol{n}_{f}\left(\varphi, \varphi_{c}, d_{s}\right)=\frac{\mathrm{d} \boldsymbol{r}_{f}}{\mathrm{~d} \varphi} \times \frac{\mathrm{d} \boldsymbol{r}_{f}}{\mathrm{~d} d_{s}} /\left|\frac{\mathrm{d} \boldsymbol{r}_{f}}{\mathrm{~d} \varphi} \times \frac{\mathrm{d} \boldsymbol{r}_{f}}{\mathrm{~d} d_{s}}\right|
$$

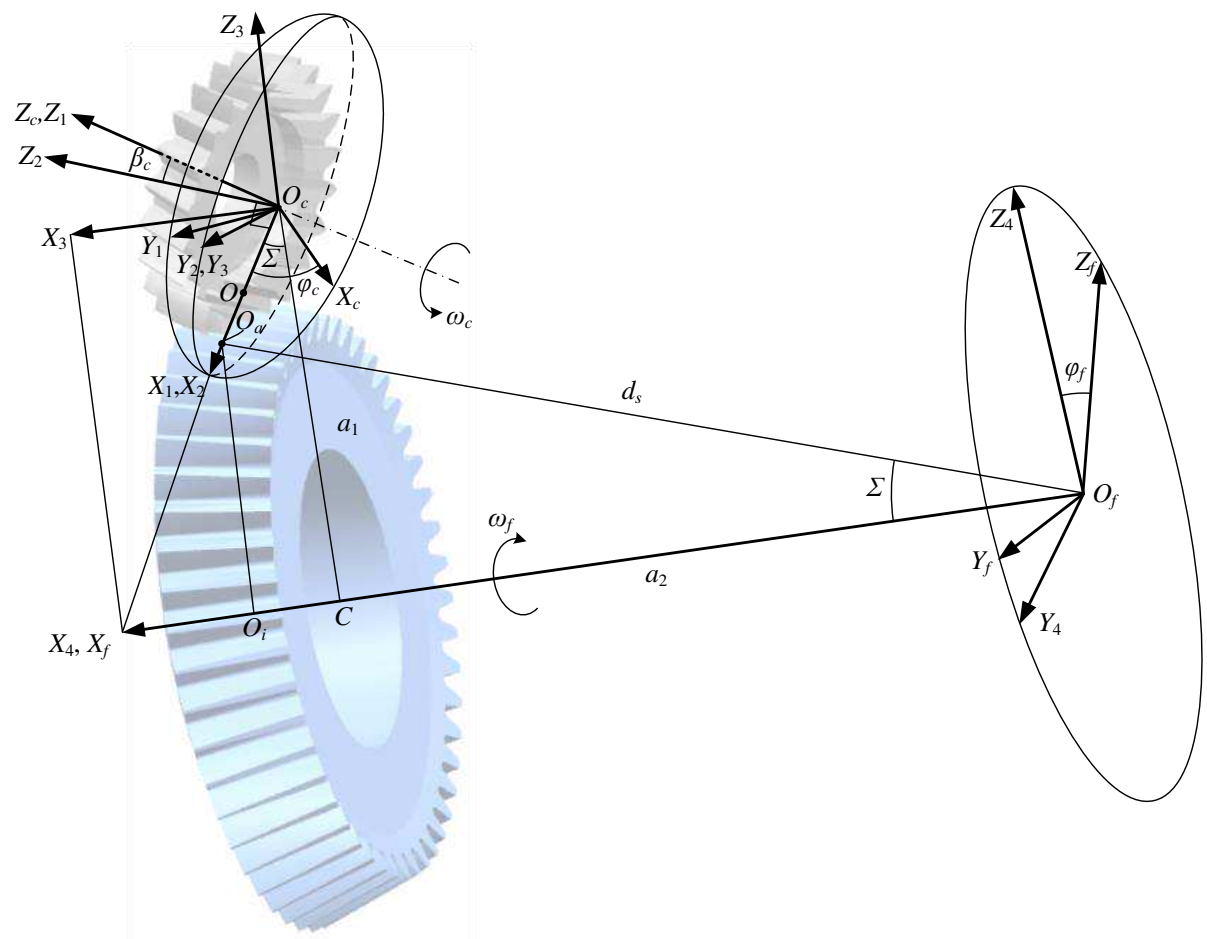

Fig. 3 Machining coordinate system

Equation (3) represents the tooth surface equation of the non-orthogonal face gear taking the vertex of the pitch cone as the origin of coordinates. This expression should meet the meshing equation as Eq. (7).

$$
f_{1}\left(\varphi, d_{s}, \varphi_{c}\right)=\frac{\mathrm{d} \boldsymbol{r}_{f}}{\mathrm{~d} \varphi} \times \frac{\mathrm{d} \boldsymbol{r}_{f}}{\mathrm{~d} d_{s}} \cdot \frac{\mathrm{d} \boldsymbol{r}_{f}}{\mathrm{~d} \varphi_{c}}=0
$$

The three-dimensional coordinates of any point on the tooth surface of the non-orthogonal face gear can be obtained by solving nonlinear equations when the axial and radial positions of the point 
are provided.

\section{Machining approach}

\subsection{Six-axis machine tool}

From the analysis of section 2, it can be seen that the machining of non-orthogonal face gears by power skiving requires three basic motions, that is, the rotation of the cutter, the rotation of the workpiece and the feed motion of the cutter relative to the workpiece. However, in view of the diversity of the shaft angle of non-orthogonal face gears, the structure of the machine tool with variable axis angles in Fig. 4 can be a suitable choice. The machine tool consists of three linear motions (X, Y, Z) and three rotary motions (A, B, C). In the process of machining, the three linear motions can realize the feed motion and in-feed adjustment along any direction of three-dimensional space through interpolation work. The two rotary motions (A, B) can meet the required position and speed of the cutter and workpiece at any time. Axis $\mathrm{C}$ is used for adjusting the angle between axis $\mathrm{A}$ and axis B. The power skiving cutter will be installed on axis $\mathrm{A}$ and the non-orthogonal face gear will be installed on axis B. The rotational speed or angular coordinate at any time of the two can be controlled by CNC system.

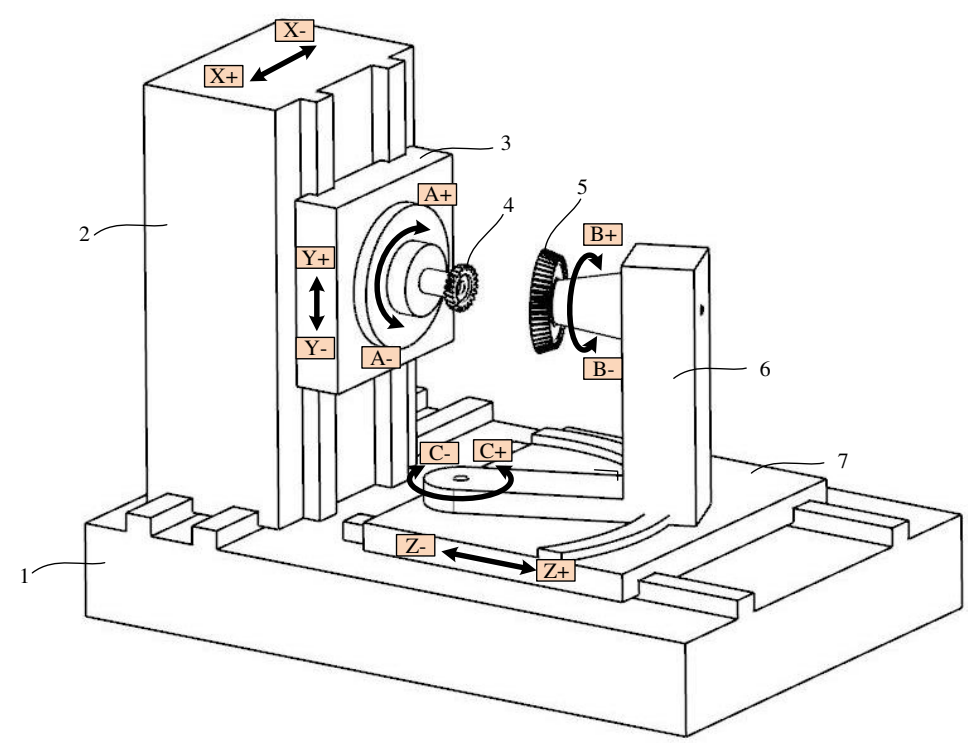

1-machine base, 2-machine column, 3-toolbox, 4-power skiving cutter, 5-non-orthogonal face gear, 6-workpiece box, 7-Sliding table

Fig.4 Six-axis machine tool

\subsection{Machine tool movement conversion}

The three motions should be strictly controlled during the process. For the rotation movement of the cutter and the workpiece, the rotary geometric axis A and B can meet this condition. But for the feed movement of the cutter along the pitch cone generatrix of the workpiece, it needs to be converted to the linear geometric axis of the six-axis machine tool.

The position of the workpiece and cutter on the six-axis machine tool is shown in Fig. 5. Coordinate system $S_{m 1}$ is parallel to $S_{1}$ and its origin overlaps the origin of the machine tool coordinate system $S_{m}$. The unit vector of the axis of the workpiece can be expressed in $S_{1}$ as: 


$$
\boldsymbol{e}_{1}^{f i}=\boldsymbol{T}_{12} \boldsymbol{T}_{23} \boldsymbol{T}_{34} \boldsymbol{e}_{4}^{f i}=\left[\begin{array}{c}
\sin \Sigma \\
\sin \beta_{c} \cos \Sigma \\
\cos \beta_{c} \cos \Sigma
\end{array}\right]
$$

where the superscript " $f i$ " in $\boldsymbol{e}_{1}^{i}$ represents the direction from $O_{f}$ to $O_{i}$. The subscript "1" represents that it is expressed in the coordinate system $S_{1}$. The same below.

The unit vector of the workpiece axis can be expressed in the machine tool coordinate system as:

$$
\boldsymbol{e}_{m}^{f i}=\boldsymbol{T}_{m 1} \boldsymbol{e}_{1}^{f i}=\boldsymbol{T}_{m 1 m}(\chi) \boldsymbol{e}_{1 m}^{f i}=\left[\begin{array}{c}
\cos \chi \sin \Sigma+\sin \chi \sin \beta_{c} \cos \Sigma \\
\cos \chi \sin \beta_{c} \cos \Sigma-\sin \chi \sin \Sigma \\
\cos \beta_{c} \cos \Sigma
\end{array}\right]
$$

where

$$
\boldsymbol{e}_{4}^{f i}=\left[\begin{array}{lll}
1 & 0 & 0
\end{array}\right]^{T}
$$

Similarly, the unit vectors of other corresponding directions can be expressed respectively as:

$$
\begin{gathered}
\boldsymbol{e}_{m}^{i a}=\boldsymbol{T}_{m 1} \boldsymbol{T}_{12} \boldsymbol{T}_{23} \boldsymbol{T}_{34} \boldsymbol{e}_{4}^{i a}=\left[\begin{array}{c}
\sin \chi \sin \beta_{c} \sin \Sigma-\cos \chi \cos \Sigma \\
\sin \chi \cos \Sigma+\cos \chi \sin \beta_{c} \sin \Sigma \\
\cos \beta_{c} \sin \Sigma
\end{array}\right] \\
\boldsymbol{e}_{m}^{a c}=\boldsymbol{T}_{m 1} \boldsymbol{T}_{12} \boldsymbol{e}_{2}^{a c}=\left[\begin{array}{c}
-\cos \chi \\
\sin \chi \\
0
\end{array}\right] \\
\boldsymbol{e}_{m}^{a f}=\boldsymbol{T}_{m 1} \boldsymbol{T}_{12} \boldsymbol{T}_{23} \boldsymbol{T}_{34} \boldsymbol{e}_{4}^{a f}=\left[\begin{array}{c}
-\sin \chi \sin \beta_{c} \\
-\cos \chi \sin \beta_{c} \\
-\cos \beta_{c}
\end{array}\right]
\end{gathered}
$$

where $\boldsymbol{e}_{m}^{a f}$ is the unit vector of the feed motion direction of the cutter, $\boldsymbol{e}_{m}^{i a}$ is the auxiliary unit vector and $\boldsymbol{e}_{m}^{a c}$ is the unit vector of the in-feed motion direction.

Limited by the structure of the machine tool, the axis of the workpiece should only be parallel to the plane $X_{m} Z_{m}$. This means that the $Y$ component of the unit vector of the workpiece axis $\boldsymbol{e}_{m}^{i}$ must be 0 . In order to meet the placement conditions of the workpiece on the six-axis machine tool, the auxiliary angle $\chi$ can be obtained as:

$$
\chi=\arctan \left(\frac{\sin \beta_{c}}{\tan \Sigma}\right)
$$

The angle between the workpiece axis and the cutter axis, that is, the root angle of the machine tool can be expressed as:

$$
\delta_{m}=\arccos \left(\boldsymbol{e}_{1}^{f i} \cdot \boldsymbol{e}_{1}^{c}\right)=\arccos \left(\cos \beta_{c} \cos \Sigma\right)
$$

where

$$
\boldsymbol{e}_{1}^{c}=\left[\begin{array}{lll}
0 & 0 & 1
\end{array}\right]^{T}
$$



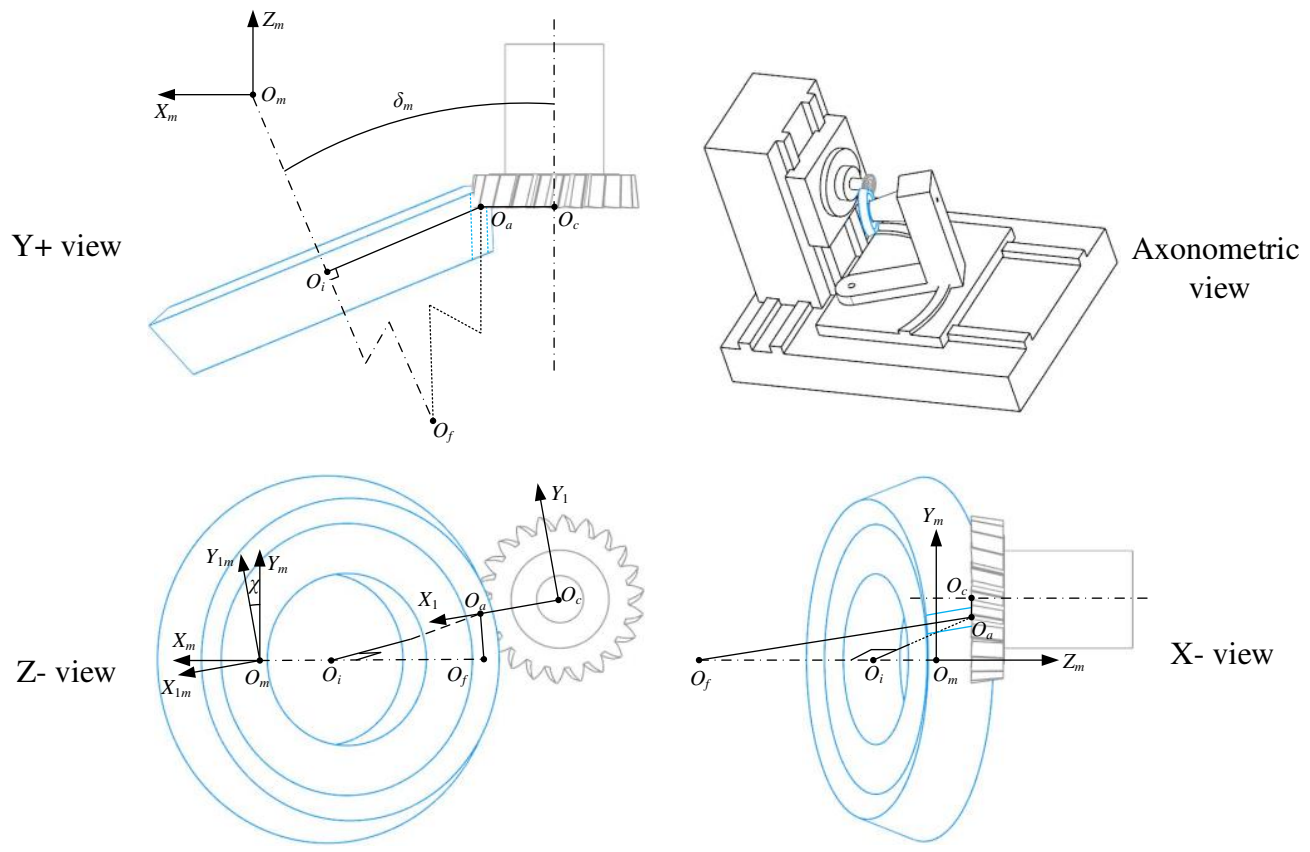

Fig. 5 Position of cutter and workpiece

According to the principle of vector superposition, the coordinates of the cutter center $O_{c}$ in the machine tool coordinate system can be expressed as:

$$
\boldsymbol{r}_{m}^{c}=\left(L_{f i}-L_{m f}\right) \boldsymbol{e}_{m}^{f i}+L_{i a} \boldsymbol{e}_{m}^{i a}+L_{a c} \boldsymbol{e}_{m}^{a c}
$$

It can be seen from Eq. (13) that the motorial direction involved in the processing of nonorthogonal face gear is only related to the shaft angle, which is between the axis of the cutter and the fictitious internal gear, and the pitch cone angle of the workpiece. When the pitch cone angle of the workpiece is zero, it means that the non-orthogonal face gear has become a cylindrical gear and the root angle of the machine tool will be the shaft angle. At this time the processing of the nonorthogonal face gear has become the processing of the cylindrical gear. When the pitch cone angle of the workpiece is $90^{\circ}$, meaning the workpiece is orthogonal face gear, the root angle of the machine tool will be $90^{\circ}$. The above formulas explain the smooth transition from orthogonal face gear to cylindrical gear.

\section{Tooth flank modification}

Modifying tooth flank is to improve the meshing performance of gear drives. Bevel gear drives are usually designed as point contact to avoid tooth edge contact. If the tooth flank of the face gear obtained by the generating gear, which has the same number of teeth as the pinion, engages with the matching pinion, the conjugate line contact will occur. This will make the face gear pair extremely sensitive to the assembly error and easy to cause edge contact. For the tooth flank of face gear generated by gear shaping method, the point contact is usually obtained by the generating gear with more 1 3 teeth than the matching pinion [6]. Too many teeth of the generating gear will increase the curvature along the tooth length direction of face gears, which will cause short contact area. Shorter contact area around the contact point will received severe stress, which is easy to produce pitting of tooth flanks, deformation, seriously shortening the service life of face gears. The way using the difference between the teeth of the generating gear and the pinion to modify tooth flanks 
has obvious limitations.

To modify face gear flanks more flexibly, the alterable in-feed along the tooth depth can be conducted. This will lead to thinning down the tooth thickness in the deeper in-feed position. In Fig. 3, $O_{c} O$ will greater than $O_{c} O_{a}$ on some selective positions. As shown in the Fig. 6, the modification curve will increase the curvature of the tooth surface of the face-gear along the tooth length direction. Because the in-feed along the tooth depth can be set by CNC system precisely, the changes in curvature along the tooth length direction can be more controlled flexibly.

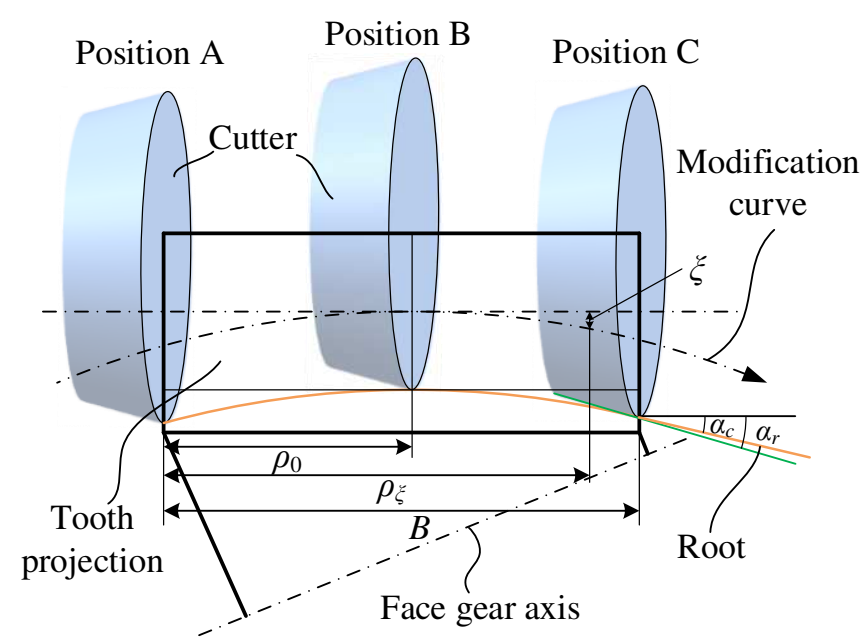

Fig. 6 Modification approach

In Fig. $6, \alpha_{r}$ is the top relief angle of the cutter. $\rho_{0}$ indicates the position of the cutter when $\xi=0$. $\rho_{\xi}$ indicates the position of the cutter at additional in-feed of $\xi$. B is the tooth width. The modification curve can be designed as variety of two-dimensional curves, such as parabola, ellipse, arc or other complex curves. Various modification methods can be obtained by providing the corresponding coefficients of these curves. In this paper, a parabola has been chosen as an example. The change of additional in-feed $\xi$ can be expressed as:

$$
\xi=a_{p r b}\left(\rho_{\xi}-\rho_{0}\right)^{2}
$$

where $a_{p r b}$ is the coefficient of the parabola. The value of it will directly affect the extent of modification.

The mathematical model of the modified tooth flank can be obtained by substituting Eq. (18) into Eq. (3).

The effect of tooth flank modification as shown in Fig. 7 can be obtained by setting appropriate modification coefficient. The tooth flank will shrink relative to the non-modified tooth of outside and inside. The modified tooth flank will be tangent to the unmodified tooth flank by a line at the inflection point of the parabola where $\rho_{\xi}=\rho_{0}$. The existence of the tangent line will ensure that the tooth thickness of the face gear at the design point will be not affected by the modifying motion. 


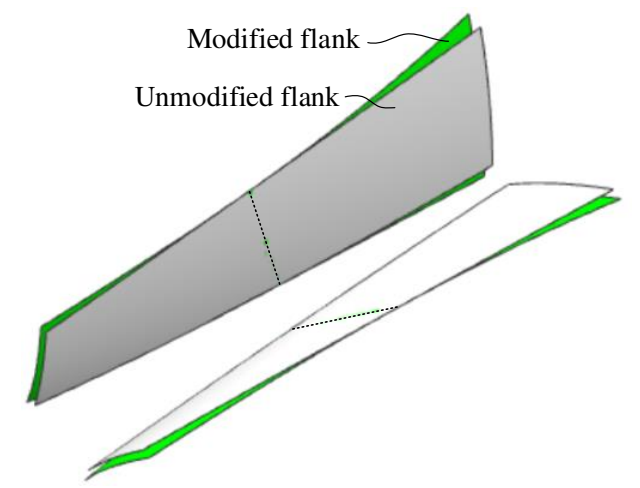

Fig. 7 Modification preconception

The cutter moves along the modified curve when the cutter is moving from the outer end to the inner end of the workpiece. This means that the tooth root curve of the non-orthogonal face gear will also be bent accordingly. Since the end face of the cutter is perpendicular to the pitch cone generatrix of the non-orthogonal face gear, the tooth root curve will be parallel to the modified curve. It can be seen from Fig. 6 that when the cutter reaches the inner end of the workpiece, the condition " $\alpha_{r}>\alpha_{c}$ " should be guaranteed to avoid interference. The upper limit of the parabolic coefficient can be expressed as:

$$
a_{p r b}<\frac{\tan \alpha_{r}}{2\left(B-\rho_{0}\right)}
$$

By substituting Eq. (19) into Eq. (18) and taking $\rho_{\xi}=B$, the maximum of modification can be obtained:

$$
\xi_{\max }=\left(B-\rho_{0}\right) \tan \alpha_{r} / 2
$$

\section{Geometric analysis of tooth flanks}

To obtain better meshing performance, it is significant to analyze the effect of modification on transmission performance of the tooth flanks of non-orthogonal face gear obtained by power skiving. The parameters are determined as shown in Table 1.

Table 1 Illustrative example

\begin{tabular}{ll}
\hline Parameters & Values \\
\hline Teeth number of the face gear & $z_{f}=44$ \\
Pressure angle & $\alpha=25^{\circ}$ \\
Module & $m=4$ \\
Helix angle of the face gear & $\beta_{f}=0$ \\
Teeth number of the pinion & $z_{p}=24$ \\
Teeth number of the cutter & $z_{c}=25$ \\
Helix angle of the cutter & $\beta_{c}=10^{\circ} \mathrm{R}$ \\
Relief angle & $\alpha_{r}=7^{\circ}$ \\
Pitch cone angle & $\Sigma=10^{\circ}$ \\
Outer pitch diameter of the face gear & $d_{o}=186 \mathrm{~mm}$ \\
Inner pitch diameter of the face gear & $d_{i}=170 \mathrm{~mm}$ \\
\hline
\end{tabular}




\subsection{Flank modification analysis}

In order to research on the gear flank more directly, the working flanks of the non-orthogonal face gear can be divided into discrete grid points. In Fig. 8, the working tooth flank is divided into $9 * 5$ nodes on the rotating projection plane of the tooth surface. $b_{i}, b_{t}, b_{o}$ and $b_{r}$ represent the inward setovers of the four boundaries of the working tooth flank, respectively. That will be beneficial to the measurement of the tooth flanks. The coordinates of grid points should meet the following formula:

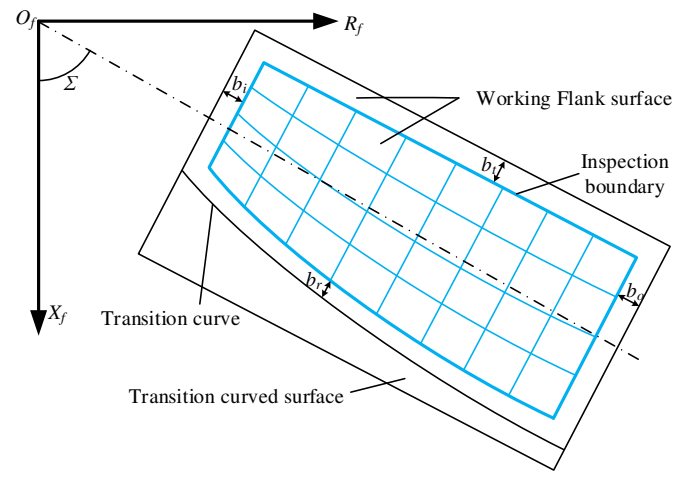

Fig. 8 Nodes on rotating projection

$$
\left\{\begin{array}{l}
x_{f}\left(\varphi, d_{s}, \varphi_{c}\right)-X_{f}=0 \\
\sqrt{y_{f}\left(\varphi, d_{s}, \varphi_{c}\right)^{2}+z_{f}\left(\varphi, d_{s}, \varphi_{c}\right)^{2}}-R_{f}=0
\end{array}\right.
$$

Equations (21) and (7) can form a system of nonlinear equations contains three parameters. Exact solutions $\left(\varphi, \varphi_{c}, d_{s}\right)$ can be obtained by providing three initial values. The corresponding threedimensional coordinates of any grid point on the tooth flank can be obtained by substituting the solutions into Eq. (3).

We regard the tooth flanks of $a_{p r b}=0$ as the reference and three different values of $a_{p r b}$ as variable factors. The changes of the modified tooth flanks can be obtained by setting $b_{i}=b_{t}=b_{o}=b_{r}=1 \mathrm{~mm}$ and $\rho_{0}=23 \mathrm{~mm}$. As shown in Fig. 9, the errors of the working tooth flank at the outer side and the inner side increase significantly with the increase of $a_{p r b}$. For example, when $a_{p r b}=0.0001$, the tip error of the outer end is $-0.025 \mathrm{~mm}$ in the left flank, but when $a_{p r b}=0.0004$, the error of the same position will be $-0.098 \mathrm{~mm}$. This will shorten the length of the tooth surface contact area. In the direction of tooth height, the change of error is not obvious. Therefore, we can predict that the variational infeed mainly affects the length of the contact area.

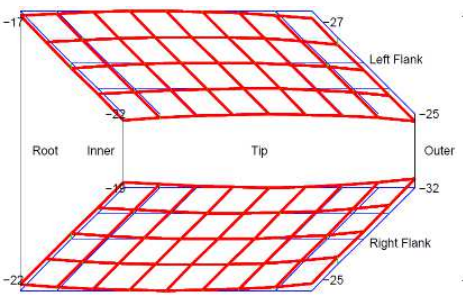

(a) $a_{p r b}=0.0001 \rho_{0}=23 \mathrm{~mm}$

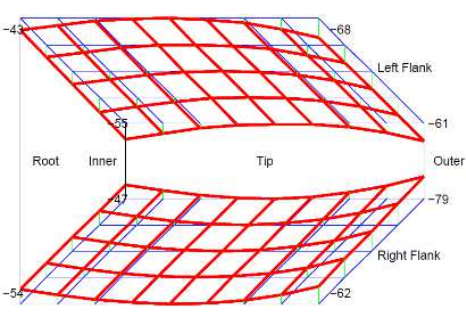

(b) $a_{p r b}=0.00025 \rho_{0}=23 \mathrm{~mm}$

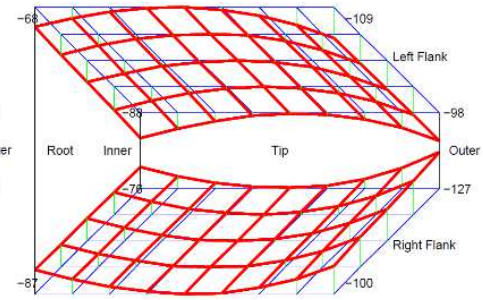

(c) $a_{p r b}=0.0004 \rho_{0}=23 \mathrm{~mm}$

Fig. 9 Tooth flank changes

\subsection{TCA and optimization}

Tooth surface contact analysis (TCA) can effectively predict tooth surface contact trace and 
transmission accuracy. Tooth surface contact needs to meet the conditions:

$$
\left\{\begin{array}{l}
\boldsymbol{M}_{m f}\left(\psi_{f}\right) \boldsymbol{r}_{f}\left(\varphi, \varphi_{c}, d_{s}\right)=\boldsymbol{M}_{m p}\left(\psi_{p}\right) \boldsymbol{r}_{p}\left(\varphi_{p}, d_{p}\right) \\
\boldsymbol{T}_{m f}\left(\psi_{f}\right) \boldsymbol{n}_{f}\left(\varphi, \varphi_{c}, d_{s}\right)=\boldsymbol{T}_{m p}\left(\psi_{p}\right) \boldsymbol{n}_{p}\left(\varphi_{p}, d_{p}\right)
\end{array}\right.
$$

where $\boldsymbol{r}_{p}$ and $\boldsymbol{n}_{p}$ represent the position vector and normal vector of the pinion, respectively. $\varphi_{p}$ and $d_{p}$ are the parameters of the tooth surface of the pinion, respectively. $\boldsymbol{M}_{m f}$ and $\boldsymbol{M}_{m p}$ respectively represent the transition matrix from the non-orthogonal face gear and pinion to the meshing coordinate system. $\psi_{f}$ and $\psi_{p}$ are the rotation angles of the non-orthogonal face gear and pinion in meshing coordinate system, respectively.

Non-orthogonal face gear processed by power skiving and the pinion with 24-tooth are used for TCA. The contact area and transmission error curves without modification are obtained as shown in Fig. 10. It can be seen from the TCA result that the tooth surface contact trace of the nonorthogonal face gear is a contact line from the inner root to the outer tip. The contact area covers almost $70 \%$ of the tooth surface. Although larger contact area can effectively reduce tooth pitting, it also increases the risk of edge contact. The transmission error is $32.25 \mu \mathrm{rad}$, which is severe in bevel gear design.

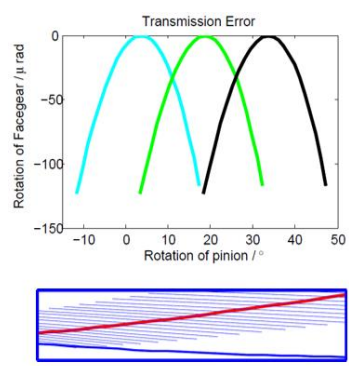

(a) Right flank

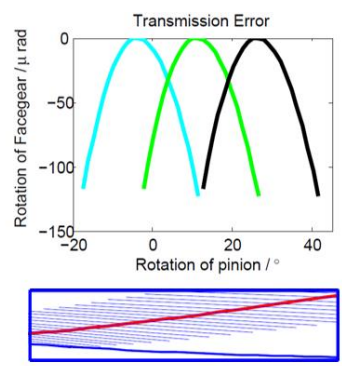

(b) Left flank

Fig. 10 TCA without modification

Taking the right tooth flank as an example, the tooth surface contact result can be obtained as shown in Fig. 11. As for the performance of the contact pattern in Fig. 11(a) (c), the contact trace of the tooth surface is close to the midpoint of the tooth width, and also inclined from the direction of the inner root to the outer tip of the tooth flank. The length of the contact ellipse also decreases with the increased value of the modification coefficient. The result is consistent with our prediction in the previous section. As for the transmission error curve, it is observed that the transmission error curves formed did not intersect with each other, which would mean that when the detachment of the prior pair of teeth is not link up the engagement of the next pair smoothly. That will cause edge contact and noise in all probability. In general, the transmission error curve is designed as approximative parabolas intersecting each other for the gear pair working effectively.

In Fig. 11(d) (f), the designed position $\rho_{0}=23 \mathrm{~mm}$ is adjusted to $\rho_{0}=28.8 \mathrm{~mm}$. It can be seen from the adjusted tooth contact result that the transmission error curve presents more reasonable distribution. The contact area also moved from the middle of the tooth to the position closed to the inner segment, but the length of the contact area did not change significantly. This can be explained that the increase of $\rho_{0}$ value will result in greater modification near the outer side and lesser near the inner side, which leads to the movement of the contact area. The change rule of the tooth surface contact status can also be used as reference for designing non-orthogonal face gear drives. 


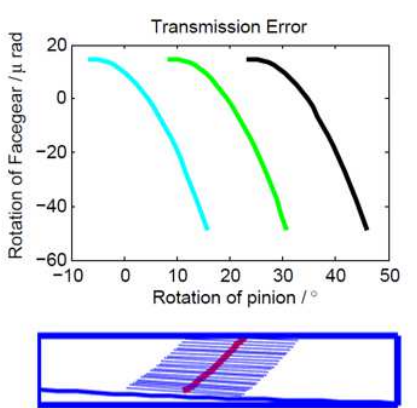

(a) $a_{p r b}=0.0001 \quad \rho_{0}=23 \mathrm{~mm}$

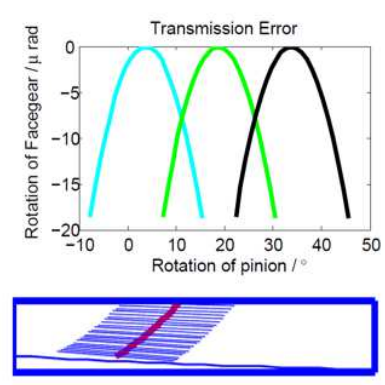

(d) $a_{p r b}=0.0001 \quad \rho_{0}=28.8 \mathrm{~mm}$

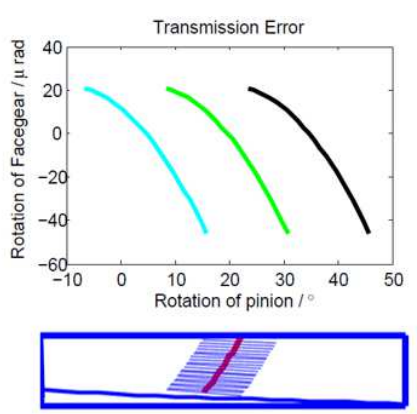

(b) $a_{p r b}=0.00025 \rho_{0}=23 \mathrm{~mm}$

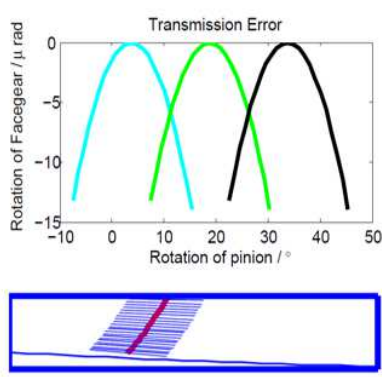

(e) $a_{\text {prb }}=0.00025 \rho_{0}=28.8 \mathrm{~mm}$

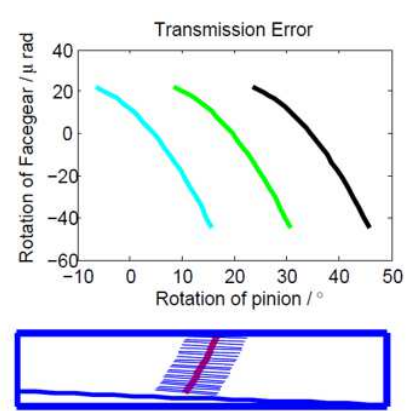

(c) $a_{p r b}=0.0004 \rho_{0}=23 \mathrm{~mm}$

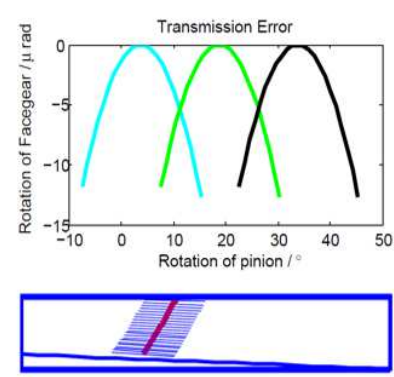

(f) $a_{p r b}=0.0004 \rho_{0}=28.8 \mathrm{~mm}$

Fig. 11 TCA after modification and adjustment

\subsection{Contact ratio analysis}

The contact ratio reflects the number of the teeth engaged at the same time in the meshing process of gear pairs. Gear drives with great contact ratio can provide excellent stability for gear transmission. A gear pair only with contact ratio greater than 1 can engage smoothly probably. The contact ratio $\varepsilon$ can be expressed by the following equation:

$$
\varepsilon=\frac{\left|\psi_{f t}-\psi_{f b}\right| z_{f}}{360^{\circ}}
$$

where $\psi_{f t}$ and $\psi_{f b}$ are the meshing angle at tooth tip and tooth root of the non-orthogonal face gear, respectively.

We define $c_{\rho}=\rho_{0} / B$ as the position of the modified reference point on the tooth surface. Fig. 12 shows the curves of the change of the contact ratio obtained by different parabolic modification coefficients and different modification positions. The contact ratio reaches the maximum value of 1.93 without flank modification. With the increasing of the modification coefficient, the contact ratio presents a decreasing trend and the decreasing speed slows down gradually. The change of the contact ratio tends to be stable when the modification coefficient is more than approximately 0.0001 . The closer the modified reference position to the outer side, the less the contact ratio will be. As the tip of the non-orthogonal face gear tooth tends to be sharp at the outer, it is easy to deform due to low strength when additional load is applied. The contact area of the face gear designed to be slightly inward will be more reasonable. 


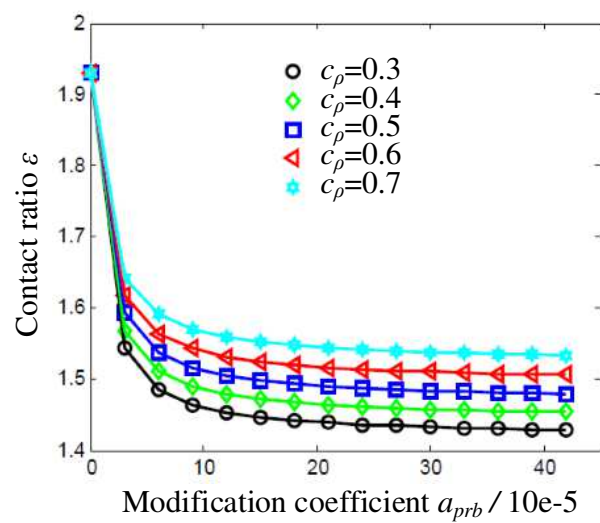

(a) Left flank

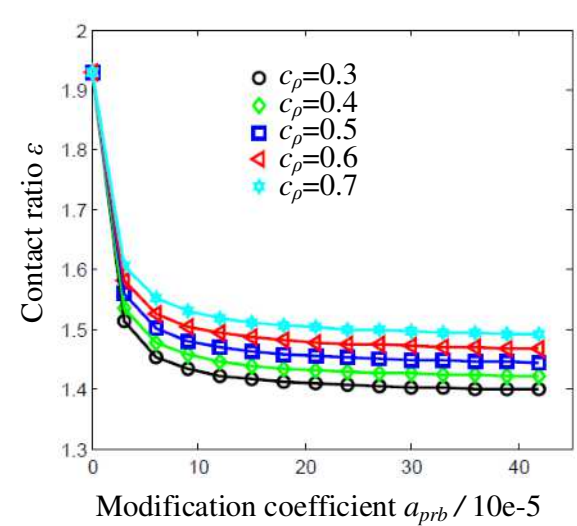

(b) Right flank

Fig. 12 Changes of the contact ratio

\section{Processing test}

This section conducts the processing test of non-orthogonal face gear by power skiving and carries on the flank measurement. The machining equipment selected is the self-developed machine tool YK2260MC, which adopts the structure shown in Fig. 4. The range of C-axis motion is from 0 to $90^{\circ}$. The workpiece axis and cutter tool axis can be accurately linked by electronic gearbox (EGB). The material of power skiving cutter is high speed steel and the rake angle is 0 . The shape of the cutting edge is standard involute. The measuring equipment is GELEASON 650GMS, which can detect the flank error of the corresponding point through the given position vector and unit normal vector. The spatial position and feed direction in the process of power skiving can be calculated by Eq. (13) and Eq. (17). Fig. 13 is the machining process of non-orthogonal face gear. The feed rate is $0.08 \mathrm{~mm}$ for each turn of the workpiece. Multiple strokes are used to avoid tool wear. The machining takes about $32 \mathrm{~min}$. Fig. 14 is the tooth surface measurement. The measurement results are shown as in Fig. 15.

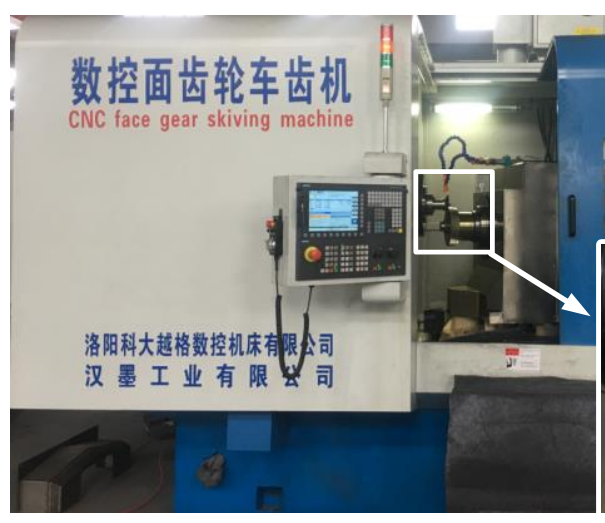

Fig. 13 Machining experiment

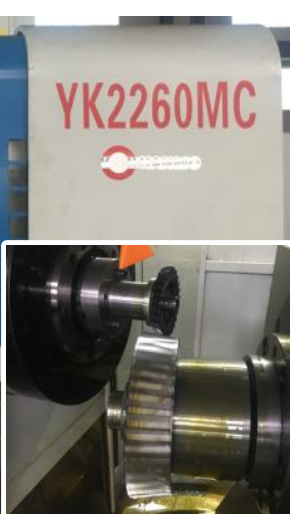

Fig. 14 Tooth surface measurement

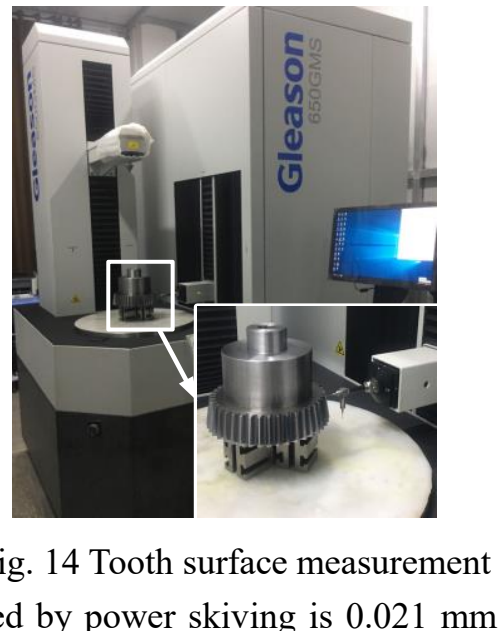

In Fig. 15(a), the maximum error of the tooth flank processed by power skiving is $0.021 \mathrm{~mm}$ compared with the theoretical flank, which is in the right tooth surface. The left tooth surface error is $0.015 \mathrm{~mm}$. Usually these errors appear due to the vibration of machine tool, the installation error of cutter and workpiece, manufacturing errors of cutter tool or other problems. The tooth surface finish will also be affected by these negative factors. However, the flank errors are within reasonable limits. Fig. 15(b) shows the topological error of the modified tooth flank. The negative errors which mainly appear at the outer side and inner side are distributed as approximately arc-shaped along the 
tooth length direction. That is consistent with the calculation results in Fig. 9(b). The experiment verifies the feasibility of machining non-orthogonal face gears by power skiving and the modification method proposed in this paper can be realized by the six-axis machine tool with the structure involved in this paper.

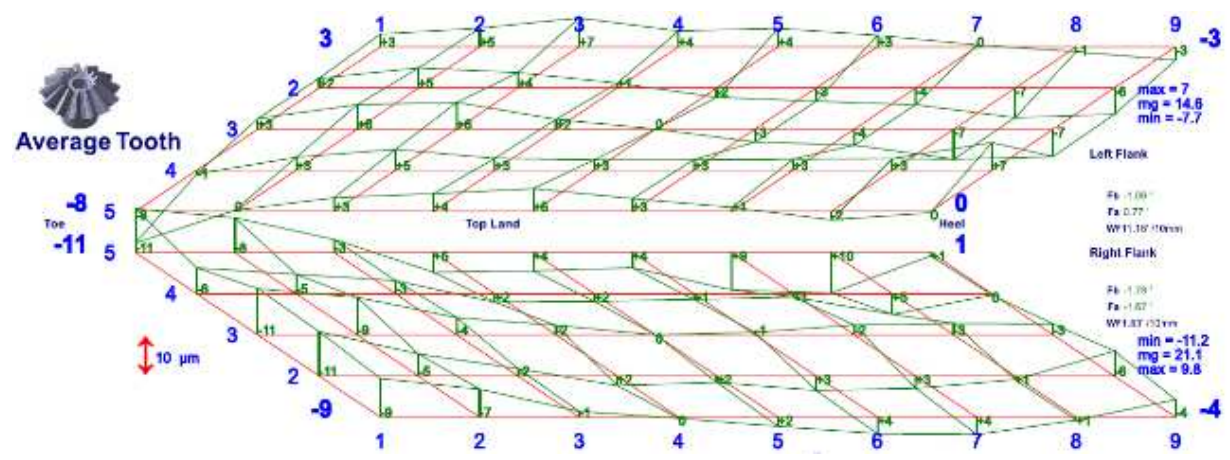

(a) Tooth flank error without modification

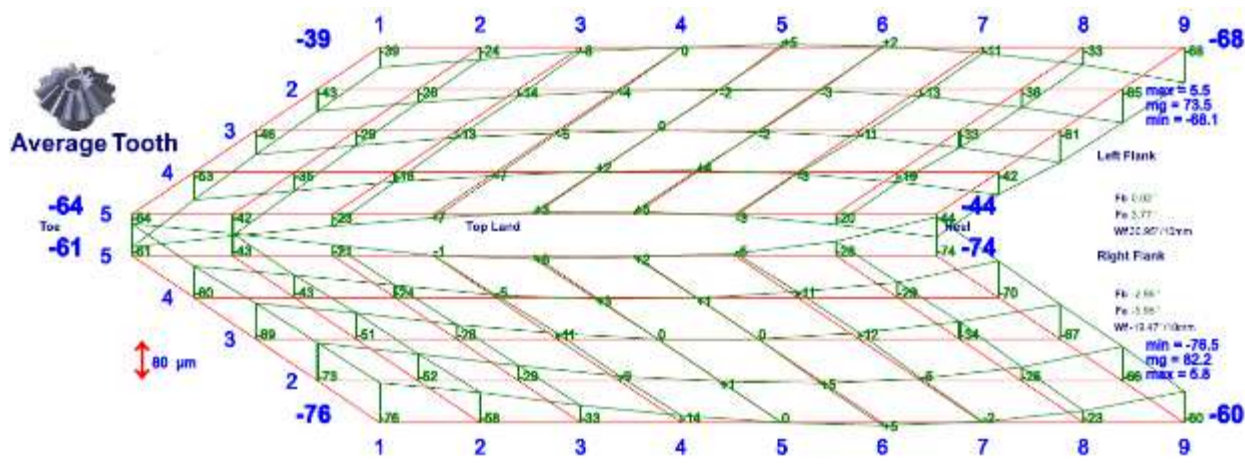

(b) Tooth flank error with modification $\left(a_{p r b}=0.00025 \rho_{0}=23 \mathrm{~mm}\right)$

Fig. 15 Tooth surface measurement results

In fact, the non-orthogonal face gear processed by power skiving is not the same as the tooth flank of the face gear proposed in reference [3]. But there are some similarities. Under special circumstances, we can assume that the shaft angle, in this paper refer to the helix angle of the power skiving cutter, is 0 . The relative motion of the cutter and the workpiece can be equivalent to the gear shaping process. Thus, the tooth surface of the cutter, or called generating cylindrical gear, and the tooth surface of the non-orthogonal face gear are completely conjugated. However, at the same time, it will also lead to the failure of producing the relative cutting speed at the tangent point of the cutter and the workpiece. The cutting ability of the cutter will lose. The difference is that in this paper, after sacrificing the condition of complete conjugation with cylindrical gear, the tooth surface of the non-orthogonal face gear is enveloped by the cutting edge of the cutter with the angle $\delta_{m}$. This kind of tooth flank will produce transmission error which can be controlled according to the design of tooth flank modification. The tooth flanks can still be meshed with cylindrical gear with small transmission error.

\section{Conclusions}

In this paper, the method machining non-orthogonal face gears by power skiving is proposed, after calculation analysis and experimental verification, the following conclusions have been obtained: 
1. The spatial position relationship between the power skiving cutter and the non-orthogonal face gear has been analyzed. The motions of the cutter and workpiece have been equivalently converted to six-axis machine tool.

2. The mathematical model of machining non-orthogonal face gears by power skiving has been established. The tooth surface data of non-orthogonal face gear has been obtained.

3. Based on the structure of six-axis machine tool, a modification method that changing the infeed movement has been proposed to optimize the tooth flank structure. The non-orthogonal face gear flank with small transmission error has been obtained.

4. The feasibility of machining non-orthogonal face gear by power skiving and the effectiveness of gear flank modification have been proved by a processing test.

\section{Appendix A}

$$
\begin{aligned}
& \boldsymbol{M}_{1 c}=\left[\begin{array}{cccc}
\cos \varphi_{c} & \sin \varphi_{c} & 0 & 0 \\
-\sin \varphi_{c} & \cos \varphi_{c} & 0 & 0 \\
0 & 0 & 1 & 0 \\
0 & 0 & 0 & 1
\end{array}\right] \boldsymbol{M}_{21}=\left[\begin{array}{cccc}
1 & 0 & 0 & 0 \\
0 & \cos \beta_{c} & -\sin \beta_{c} & 0 \\
0 & \sin \beta_{c} & \cos \beta_{c} & 0 \\
0 & 0 & 0 & 1
\end{array}\right] \\
& \boldsymbol{M}_{32}=\left[\begin{array}{cccc}
\sin \Sigma & 0 & \cos \Sigma & 0 \\
0 & 1 & 0 & 0 \\
-\cos \Sigma & 0 & \sin \Sigma & 0 \\
0 & 0 & 0 & 1
\end{array}\right] \boldsymbol{M}_{43}=\left[\begin{array}{llll}
1 & 0 & 0 & a_{2} \\
0 & 1 & 0 & 0 \\
0 & 0 & 1 & a_{1} \\
0 & 0 & 0 & 1
\end{array}\right] \\
& \boldsymbol{M}_{f 4}=\left[\begin{array}{cccc}
1 & 0 & 0 & 0 \\
0 & \cos \varphi_{f} & \sin \varphi_{f} & 0 \\
0 & -\sin \varphi_{f} & \cos \varphi_{f} & 0 \\
0 & 0 & 0 & 1
\end{array}\right]
\end{aligned}
$$

\section{Declarations}

a. Funding information: This research is supported by the National Natural Science Foundation of China (Grant No. 51975185 and No. 52005157) and China Postdoctoral Science Foundation (No. 2021M690051).

b. Conflicts of interest/Competing interests: Not applicable

c. Availability of data and material: Not applicable

d. Code availability: Not applicable

e. Ethics approval: Not applicable

f. Consent to participate: Not applicable

g. Consent for publication: Not applicable

h. Authors' contributions: Not applicable

\section{References}

[1] Heath GF, Slaughter SC, Morris, MT, Fetty J and Fisher, DJ (2009) Face gear development under the rotorcraft drive system for the 21st century program. 65th Annual Forum Proceedings AHS International 2:1011-1030

[2] Buckingham (1949) Analytical mechanics of gears. The McGraw-Hill Book 
[3] Litvin FL, Zhang Y. and Wang JC (1992a) Design and geometry of face-gear drives, Journal of Mechanical Design. Transactions of the ASME 114(4):642-647

[4] Litvin FL, Wang J, Bossler RB, Chen, YD, Heath G and Lewicki, DG (1992b) Application of Face-Gear Drives in Helicopter Transmissions. Journal of Mechanical Design, Transactions of the ASME 116(3):672-676

[5] Litvin FL, Egelja A, Tan J and Heath G (1998) Computerized design, generation and simulation of meshing of orthogonal offset face-gear drive with a spur involute pinion with localized bearing contact. Mechanism and Machine Theory 33(1-2):87-102

[6] Litvin FL and Fuentes A (2004) Gear Geometry and Applied Theory. Cambridge University Press

[7] Wang Y, Hou L, Lan Z and Zhang G (2016) Precision grinding technology for complex surface of aero face-gear. International Journal of Advanced Manufacturing Technology 86(5-8):12631272

[8] Wang Y, Lan Z, Hou L, Chu X and Yin Y (2017) An efficient honing method for face gear with tooth profile modification. International Journal of Advanced Manufacturing Technology 90(14):1155-1163

[9] Chu X, Wang Y, Du S, Huang Y and Su G (2020) An efficient generation grinding method for spur face gear along contact trace using disk CBN wheel. International Journal of Advanced Manufacturing Technology 110(5-6):1179-1187

[10] Kawasaki K, Tsuji I and Gunbara, H (2018) Geometric design of a face gear drive with a helical pinion. Journal of Mechanical Science and Technology 32(4):1653-1659

[11] Kin'ichi S, Masafumi S and Md.Rezaur R (1978) Development of a New Type Cutter "Revolving Type Pinion Cutter" for the Hobbing of the Face Gear. Bull JSME 21(155):899906

[12] Hermann J (2011) CONIFACE Face Gear Cutting and Grinding. American Gear Manufacturers Association Fall Technical Meeting :1-14

[13] Von Pittler W (1910) Verfahren zum Schneiden von Zahnrädern mittels eines zahnradartigen, an den Stirnflächen der Zähne mit Schneidkanten versehenen Schneidwerkzeugs, Deutsche Patentschrift Nr. 243514.

[14] Guo E, Hong R, Huang X and Fang C (2014) Research on the design of skiving tool for machining involute gears. Journal of Mechanical Science and Technology 28(12):5107-5115

[15] Guo E, Hong R, Huang X and Fang C (2015) Research on the cutting mechanism of cylindrical gear power skiving. International Journal of Advanced Manufacturing Technology 79(14):541-550

[16] Spath D and Hühsam A (2002) Skiving for high-performance machining of periodic structures. CIRP Annals - Manufacturing Technology 51(1):91-94 